Jurnal PG-PAUD Trunojoyo: Jurnal Pendidikan dan Pembelajaran Anak Usia Dini, Volume 8, Nomor 2, Oktober 2021, hal 1-9, ISSN: 2528-3553 (online), ISSN: 2407-4454 (print)

\title{
IMPLEMENTASI MODEL PEMBELAJARAN SENTRA BAHAN ALAM UNTUK MENINGKATKAN KREATIVITAS ANAK USIA 4-5 TAHUN
}

\author{
Asyiful Munar ${ }^{1}$ \\ Hibana ${ }^{2}$ \\ Susilo Surahman ${ }^{3}$ \\ ${ }^{1,2}$ Programstudi Magister PIAUD UIN Sunan Kalijaga Yogyakarta, ${ }^{3}$ Programstudi Hukum Ekonomi \\ Syariah IAIN Surakarta \\ Email: munarasyiful@gmail.com, hibana@uin-suka.ac.id, susilo.surahman@iain-surakarta.ac.id
}

Received (July), Accepted (September), Published (October)

\begin{abstract}
Implementation of Natural Material Center Learning Model to Increase the Creativity of 4-5 Years Old Children. Early childhood has various abilities that need stimulation, at this institution still applying the classical learning model, where in this classical model the teacher is most highlighted as the main role in learning. In order to meet the needs of increasing creativity for children, TKN Pembina Sawang wants to apply a natural material center learning model to foster creativity in children. This research is in the form of field research with qualitative methods. The results of observations made to teachers who were held three times at the beginning of learning until they were finished with the natural material center, the researchers found that the natural material center learning to increase children's creativity through banana stem natural materials had developed very well. This can be seen in children aged 4-5 years who are able to create their own various forms through the medium of banana midrib. Based on the symptoms found in the field, suggestions from researchers: in making the RPPH it is expected to include the KD (competency standard). So that what is to be achieved in the learning process can be carried out properly. It is expected that teachers in implementing this natural material center learning model use materials that exist in nature that have been encountered and are familiar to children, anything can be done as long as it does not endanger the child and is always under the supervision of the teacher and in accordance with the child's developmental stage.
\end{abstract}

Keywords: natural materials center learning model, creativity, early childhood.

Abstrak: Implementasi Model Pembelajaran Sentra Bahan Alam Untuk Meningkatkan Kreativitas Anak Usia 4-5 Tahun. Anak usia dini memiliki berbagai kemampuan yang perlu adanya stimulasi, pada lembaga ini masih menerapkan model pembelajaran klasikal, dimana pada model klasika ini yang paling ditonjolkan guru sebagai peran utama dalam pembelajaran. Dalam rangka untuk memenuhi kebutuhan peningkatan kreativitas bagi anak, TKN Pembina Sawang ingin menerapkan model pembelajaran sentra bahan alam untuk menumbuhkan kerativitas yang dimiliki anak. Penelitian ini berupa penelitian lapangan (field research) dengan metode kualitatif. Hasil observasi yang dilakukan terhadap guru yang dilakukan tiga kali pertemuan pada awal pembelajaran sampai selesai dengan sentra bahan alam, peneliti mendapati bahawa pembelajran sentra bahan alam untuk meningkatkan kreativitas anak melalui bahan alam pelepah pisang sudah berkembang dengan sangat baik. Hal ini terlihat pada anak umur 4-5 tahun sudah mampu mengkreasikan sendiri berbagai macam bentuk-bentuk melalui media pelepah pisang. Berdasarkan gejala yang terdapa dilapangan, saran dari peneliti: didalam pembuatan RPPH diharapkan untuk mencantumkan KD (standar kompetensi). Agar apa yang ingin dicapai dalam proses pembelajaran dapat dilaksanakan dengan baik. Diharapkan kepada guru dalam penerpan model pembelajaran sentra bahan alam ini untuk menggunakan bahan yang ada dialam yang udah dijumpai dan tidak asing bagi anak, bisa apa saja asalkan tidak membahayakan anak dan selalu dalam pengawasan guru serta sesuai dengan tahap perkembangan anak.

Kata Kunci: model pembelajaran sentra bahan alam, kreativitas, anak usia dini.

Copyright (c) 2021 Asyiful Munar, Hibana, Susilo Surahman 
Jurnal PG-PAUD Trunojoyo: Jurnal Pendidikan dan Pembelajaran Anak Usia Dini, Volume 8, Nomor 2, Oktober 2021, hal 1-9, ISSN: 2528-3553 (online), ISSN: 2407-4454 (print)

\section{PENDAHULUAN}

Berbeda dengan anak yang sudah memasuki jenjang pembinaan lanjutan, anak usia 0-6 tahun sedang menjalani masa keemasan yang biasa disebeut dengan the golden age dalam kehidupannya. Pada usia ini anak sedang jalani masa-masa krusial, biasanya orang dewasa menyebutnya dengan sebutan fase kritis, dalam tumbuh kembang anak. Oleh demikian, anak-anak memerlukan perlakuan (treatment) yang tepat dari orang dewasa dilingkungannya berupa pengasuhan dan pendidikan yang tepat yang memiliki tujuan utama berupa memberi stimulasi bagi tumbuh kembang secara optimal. Pemberian stimulasi yang tepat, setiap anak tentu saja akan tumbuh dan berkembang secara baik. Sebaliknya, jika stimulasi yang ia terima tidak tepat, maka bisa berakibat potensi tidak akan berkembang dengan sempurna atau ada gangguan dalam satu atau beberapa aspek perkembangannya (Rasyid, 2020)

Hakikatnya anak sejak lahir sudah memiliki potensial namun untuk meningkatkan potesi tersebut perlunya stimulasi dari orang dewasa. Hal ini sudah ditetapkan dalam kebijakan perundanganundangan Tahun 2003, Nomor 20 menetapkan bahwasanya pembelajar pada usia 0-6 tahun merupakan salah satu usaha yang ditujukan kepada semua anak, perlu adanya sarana memberikan rangsangan pendidikan agar mendukung pertumbuhan dan perkembangan baik berupa fisik serta motorik, perkembangan intelektual, yang diberikan sejak anak lahir kedunia sampai usia enam tahun, supaya setiap anak memiliki kecakapan yang matang untuk merambah pada jenjang pendidikan setelahnya (Nasional, 2004).

Anak yang berusia pada 0-6 tahun merupakan istilah yang disimbolkan kepada mereka yang masih berada di usia prasekolah. Pada masa-masa inilah anak berkembang dengan baik sesuai dengan pola asuh orangtua dan juga pengaruh dari lingkungannya. Anak pada usia 0-6 tahun adalah sekumpulan anak yang tengah menjalani setiap proses pertumbuhan yang memiliki sifat yang sangat menarik (unik). Yaitu, pola perkebangan dan pertumbuhan (koordinasi saling berkaitan antara motorik halus dan kasar), kecakapan bersifat (rasio, kreativitas, kecerdasan dalam sikap, dan penegtahuan tentang keagamaan), sosial emosioanal (tingkah laku), bahasa, dan komunikasi yang tepat selaras dengan tahap tumbuhan dan kembangan anak (Suyadi, 2014). Oleh sebab itu, dilihat dari kemampuan yang besar yang ada dalam pribadi setiap anak yang harus dikembangkan oleh lingkungan sekitar (Susanti, 2012), dengan beberapa caranya yaitu dengan menyediakan fasilitas pendidikan pada jenjang atau lembaga PAUD.

Hasil observasi awal yang dilakukan analisis melihat bahwa anak 4-5 tahun belum mampu mengembangkan kreativitas secara bebas dikarenakan sistem pembelajaran yang digunakan hanya berfokus kepada pendidik. Dalam rangka untuk memenuhi kebutuhan peningkatan kreativitas bagi anak, TKN Pembina Sawang ingin mengimplementasikan model pembelajaran sentra bahan alam untuk meningkatkan kerativitas yang dimiliki anak.

Menurut kepala sekolah di TKN Pembina Sawang, pada lembaga ini masih menerapkan model pembelajaran klasikal, dimana pada model klasika ini yang paling ditonjolkan guru sebagai peran utama dalam pembelajaran. Mengingat dengan permasalah tersebut analisis ingin menerapkan model pembelajaran sentra bahan alam untuk peningkatkan kreativitas pada anak di TKN Pembina Sawang. Tujuan lain dari penelitian ini ingin mendapatkan gambaran proses pengembangan kreativitas pada anak usia 4-5 tahun melalui model pembelajaran sentra bahan alam, dimana untuk menghasilkan data ini penulis melalui 
Jurnal PG-PAUD Trunojoyo: Jurnal Pendidikan dan Pembelajaran Anak Usia Dini, Volume 8, Nomor 2, Oktober 2021, hal 1-9, ISSN: 2528-3553 (online), ISSN: 2407-4454 (print)

temuan-temuan dilapangan oleh karena itu peneliti memilih pendekatan kualitatif ini.

\section{Kreativitas}

Supriadi mengatakan dalam buku Rachmawati bahwa, "kreativitas berupa kemampuan setiap orang untuk memunculkan suatu yang baru, baik karya nyata ataupun pemikiran, yang pasti tidak sama dengan wujud yang telah ada. Kreativitas berupakan kemampuan berimajinasi tingkat tinggi" (Rachmawati, 2011). Kreativitas merupakan penemuan terhadap sesuatu, baik yang baru atau pengembangan terhadap sesuatu yang telah terwujud, kreativitas muncul dari cara berfikir yang berbeda, sehingga menghasilkan seni yang dapat dijadikan pengetahuan atau pelajaran yang baru. Kreativitas menurut Gordon dan Brow "Kreativitas berupakan keterampilan setiap anak dalam menciptakan suatu gagasan baru, baik berupa imajinasi, dan juga keterampilan mengolah setiap pemikiran baru dengan gagasan yang sudah ada atau dimiliki" (Freeman, 2004). Kreativitas merupakan kemampuan anak mengembangkan imajinasi yang muncul secara natural tanpa ada penciplakan, imajinasi ini muncul dari sesuatu yang dilihat atau di dengar, sehingga menghasilkan seni keindahan bagi yang melihatnya.

Berdasarkan beberapa pendapat diatas maka dapat diambil kesimpulkan yaitu kreativitas berupa keterampilan perorangan untuk menampilkan pandangan yang baru, sepeti penemuan baru atau pengembangan terhadap sesuatu yang telah ada, kreativitas muncul dengan berbagai pandangan yang berbeda, kreativitas juga merupakan imajinasi yang tidak terbatas, baik berupa bentuk, seni atau teknologi, sehingga menghasilkan keindahan dan pengetahuan bagi yang melihat atau mengguanakannya.

Guilford menyatakan dalam buku Munandar, ada beberapa ciri-ciri kreativitas diantaranya adalah (a) kefasihan dalam berpikir dengan kata lain ialah kemampuan dalam menciptakan gagasan baru yang muncul dari pemikiran seseorang secara cepat, (b) elaborasi atau kemampuan dalam menguraikan setiap gagagsan dan meningkatan atau memperjelas detail terhadap sebuah objek, tanggapan sehingga menjadi sesuatu yang lebih menarik, (c) originalitas yaitu keahlian dalam melahirkan suatu gagasan unik atau kemampuan untuk melahirkan gagasan yang bersifat original (asli) (Munandar, 2009).

Kreativitas menurut Nurhayati antaranya yaitu: (a) memperlihatkan rasa ingin tahu yang teramat sangat atau dengan kata lain tertarik akan hal-hal yang baru, (b) menciptakan beberapa macam gagasan guna menyelasikan persoalan yang ada, (c) mengajukan pertanyaan yang unik dan pintar sesering mungkin, misalnya jika sedang diskusi anak berani memberikan tanggapan, (d) suka mencoba hal baru (Nurhayati, 2011).

Berdasarkan ciri-ciri kreativitas di atas bahwasannya jika anak dapat berpikir dengan baik kemudian menumbuhkan ideide baru dengan menggunakan media yang sudah disediakan, kemudian anak menambahkan dan mencapur bahan atau media yang lain, sehingga menjadi suatu bentuk yang lebih menarik dan mempunyai nilai keindahan maka pada saat itu kreativitas seni anak telah muncul.

Indikator kreativitas anak usia dini yang perlu dikembangkan sesuai dengan teori perkembangan yaitu: mampu menghasikan karya, memiliki rasa ingin tahu yang tinggi, mampu mengerjakan sesuatu sendiri tanpa adanya bantuan pendidik, mampu menjawab pertanyaan sederhana, dan bertanggung jawab atas tugas yang diberikan (Suhartini, 2016). Adapun kreativitas anak dapat dimunjulkan melalui kegiatan-kegiatan yang tersedikan disetiap sentra salah satunya dengan bereksplorasi, 
Jurnal PG-PAUD Trunojoyo: Jurnal Pendidikan dan Pembelajaran Anak Usia Dini, Volume 8, Nomor 2, Oktober 2021, hal 1-9, ISSN: 2528-3553 (online), ISSN: 2407-4454 (print)

dengan bereksplorasi anak dapat menemukan hal-hal baru yang dapat meningkatkan kreativitas yang dimilikinya.

\section{Model Pembelajaran Sentra}

Kata Sentra bersumber dari kata "center" yang memiliki arti berfokus pada suatu titik atau keahlian, seluruh kegiatan yang disalurkan oleh pendidik kepada setiap anak dengan tindakan-tindakan yang telah dipikirkan dan direncanakan agar dapat dikelompokkan secara terurut, tersistem, dan memiliki tujuan yang terarah, sehingga setiap anak dapat membentuk kemampuas dalam menelaah dan mempunyai kesanggupan dalam mengambil setiap kesimpulan. Sentra memiliki makna bahwa setiap aktifitas yang dilakukan pada seluruh sentra yang disediakan mempunyai titik pusat atau fokus (center poin), yang semuanya mengacu untuk tujuan belajar (Retno soendari, 2010).

Bentuk Pembelajaran sentra atau yang biasa disebut dengan BCCT (Beyond center circle time) adalah satu acuan pembinaan pada anak usia dini yang memilik titik fokus pada sentra-sentra dan lingkungan (Lestarini et al., 2013). Pembelajaran sentra dan lingkaran ini adalah titik fokus pembelajar atau sumber belajar yang merupakan salah satu acuan yang terencana guna agar dapat menstimulasi setiap perspektif perkembangan pada anak pada rentan usia 06 tahun. Perkembangan yang dimaksud mencakup perkembangan dan rangsangan beragam potensi yang sudah dimiliki anak secara natural sejak lahir. Lewat model pembelajaran sentra ini anak bisa belajar lebih aktif dan termotifasi (Sudjarwo, 2009). Pembelajaran sentra bertujuan untuk upaya mendatangkan dan memperkenalkan kepada anak dalam dunia sesunggnya (nyata) yang disusun kedalam wujud sentra. Di setiap sentra anak akan mencicipi hal-hal baru berupa menggabungkan pengetahuan yang sudah dimilikin dengan mempraktikkan kedalam kehidupan setiap harinya (Dahlia, 2014). Pendapat sujiono mengenai tujuan model pembelajaran sentra yaitu: bertujuan untuk merangsang seluruh aspek kecerdasan majemuk melalui kegiatan bermain, disiapkan untuk merangsang anak untuk aktif dan dapat berfikir secara kreatif, berpusat pada sentra-sentra (Ghofur, 2017).

Menurut Soendari (Ghofur, 2017) kelebihan pembelajaran sentra adalah menggunakan model pembelajaran individual yang disesuaikan dengan minat, bakat dan pertumbuhan perkembangan anak. Model pembelajaran memiliki kelebihan yaitu: mampu memberikan pengalaman bermain secara lebih lengkap dan mendalam melalaui pembagian sentra-sentra. Kelebihan lainnya adalah pendekatan ini lebih fleksibel dan konstektual sehingga model pembelajaran ini lebih sesuai dengan kurikulum tingkat satuan pendidikan (Hafiza, 2019).

Model pembelajaran sentra merupakan pendekatan yang diterapkan pada suatu lembaga yang memiliki titik fokus bagi setiap anak yang berada pada proses pembelajaran berfokus pada sentra bermain yang tatkala anak pada lingkaran dengan menerapkan 4 model scaffolding (pijakan) untuk membantu setiap pertumbuhan anak, berupa: pijakan lingkungan bermain, pijakan sebelum bermain, pijakan selama bermain, pijakan setelah bermain (Depdiknas, 2007). Pada model pembelajaran sentra anak fokus belajar sambil bermain, Ada beberapa macam sentra bermain (Yusuf, 2018), sebagai berikut: 1) Sentra iman dan takwa, sejak dini anak perlu ditanamkan nilai keagaman. 2) Sentra balok, sarana bermain anak dalam meningkatkan kemampuan visual spasial. 3) Sentra bermain peran kecil(mikro) dan peran besar, memberikan fasilitas kepada anak untuk meninkatkan kosakata dan interaksi sosial. (4) Sentra seni, bertujuan memberikan peluang kepada anak untuk menonjolkan macam-macam keahlian 
Jurnal PG-PAUD Trunojoyo: Jurnal Pendidikan dan Pembelajaran Anak Usia Dini, Volume 8, Nomor 2, Oktober 2021, hal 1-9, ISSN: 2528-3553 (online), ISSN: 2407-4454 (print)

yang berkaitan dengan seni berupa musik, tari, kriya, pahat. Seni yang ingin dikembangkan tergantung kepada setiap kemampuan dan kesepakatan setiap satuan lembaga PAUD. (5) Sentra persiapan, merupakan pemberikan keleluasaan pada anak untuk mengeksporasikan kemampuan baca tulis dan berhitung, mengenal angka, bentuk dan lain sebegainya. (6) Sentra bahan alam, kesempatan bagi anak untuk berbagi pengalaman dalam bereksporasi pada setiap kegiatan yang disediakan bersumber dari alam sekitar berupa, air, pasir, bebatuan, dedaunan. (7) Sentra memasak, pada sentra ini anak bisa mengenal konsep matematika, sains, alam, dan sosial.

Sentra bahan alam bertujan untuk memberi fasilitas kepada anak agar dapat membangun kemampuan kreativitas yang dimiliki anak dengan bermacam rupa peralatan atau bahan yang berasal dari alam sekitar dan bisa dijumpai dalam kehidupan sehari-hari. Adapun kegiatan yang ada pada sentra bahan alam adalah kegiatan pengembangan dari bahan yang bersifat cair, yang biasanya memanfaatkan bahan berupa fluid, seperti: air, pasir, biji-bijian, tepungtepungan, kegiatan menimbang dan memuat, mengisi, dan peninjauan pada suatu peristiwa sains (mukhtar latif, 2013).

\section{METODE}

Peneliti memilih penelitian lapangan (field research) yang bertujuan untuk melihat fenomena-fenomena yang terdapa dilapangan. Mengenai metode yang menjadi acuan pada penelitian ini berupa metode kualitatif. Teknik pengumpulan data pada penelitian ini berupa observasi dan wawancara. Peneliti ingin mengumpulkan data apa saja yang mampu meningkatkan kreativitas anak dalam pembelajaran model sentra bahan alam menggunakan pelepah pisang yang terdapat dilapangan. Sebelum penelitian ini dilakukan, peneliti terlebih dahulu mendatangi kepala sekolah dengan tujuan untuk meminta kesediaan untuk melakukan penelitian di TKN Pembina Sawang. Selanjutnya guru harus mempersiapkan RPPM dan RPPH sebagai keadministrasian sebelum belajar mengajar berlangsung. Peneliti melakukan pengamatan selama tiga kali pertemuan.

Langkah-langkah dalam melakukan penelitian yaitu:

1. Meminta izin penelitian kepada kepala sekolah

2. Membuat kerangka RPPH sesuai dengan tema yang dipilih agar proses pembelajar sesuai dengan KTSP

3. Melihat aktivitas guru selama proses pembelajaran berlangsung

Data dikumpulakan melalui hasi dari observasi dan wawancara yang dilakukan pada guru din TKN Pembina Sawang Aceh Utara.

\section{HASIL DAN PEMBAHASAN \\ Gambaran Lokasi Penelitian}

Berikut rekaan tempat penelitian ini dilakukan, TKN Pembina Sawang Aceh Utara yang terletak di kecamatan tepatnya di J1. Balee Aron, Dusun Kuta Batee, kecamatan Sawang, kabupaten Aceh Utara. lingkungan TKN Pembina Sawang merupakan lingkungan pendidikan dan kantor juga pasar, pada posisi seperti ini menjadikan TKN Pembina Sawang yang stragis bagi jangkauan banyak masyarakat dan juga perlu pengawasan yang ketat bagi guru dikarenakan berdekatan dengan pasar. Hal ini dikarenakan jalur sekolah merupakan lintasan utama untuk semua transportasi pribadi maupun umum dan juga masyarakat menilai atau merasa bahwa sekolah mudah untuk dijangkau.

\section{Hasil Penelitian}

Implementasi model pembelajaran sentra bahan alam untuk meningkatkan kreativitas pada anak usia 4-5 tahun di TKN Pembina Sawang. Menurut pengamatan peneliti dan 
Jurnal PG-PAUD Trunojoyo: Jurnal Pendidikan dan Pembelajaran Anak Usia Dini, Volume 8, Nomor 2, Oktober 2021, hal 1-9, ISSN: 2528-3553 (online), ISSN: 2407-4454 (print)

wawancara dengan guru kelas bahwa sebelum memulai kegiatan pembelajaran guru terlebih dahulu mempersiapkan ranjangan propram pembelajaran harian yang telah disesuaiakan dengan tema dan indikator yang sesuai dengn tahap perkembangan anak, menyiapkan lingkungan atau ruang dan menyiapkan media yang berkenaan dengan sentra bahan alam. Proses penyiapan tersebut tentu biasanya disiapkan sehari sebelum pembelajaran berlangsung, biasanya disiapkan pada saat proses pembelajaran selesai pada saat anak-anak sudah pulang atau disiapkan dirumah, hal ini dilakukan agar pada saat proses pembelajarn berlangsung tidak akan terjadi hal-hal yang tidak diinginkan. Adapun media sentra bahan alam yang disiapkan berupa pelepah pisang, kertas, cat pewarna, spidol. Media tersebut mudah digunakan dan bisa digunakan dalam berbagai macam bentuk yang diinginkan anak, dengan media sentra bahan alam menggunakan pelepah pisang anak-anak merasa senang dan tidak membosankan sehingga anak-anak lebih mudah dalam meningkatkan kreativitas melalui media tersebut.

Dari hasil pengamatan peneliti yang dilakukan selama tiga kali pertemuan menggunakan media yang sama berupa pelepah pisang, terlihat bahwa dalam perencanaan sentra bahan alam terlebih dahulu guru menyusun bahan-bahan yang hendak dipakai pada saat preses belajar mengajar dan disiapkan pada saat proses pembelajaran selesai ketika anak pulang. Pada saat proses pembelajarn berlangsung peneliti mendapati bahwad dalam hal ini dilihat anak memliki antusias yang tinggi pada saat kegiatan berlangsung.

Sealanjutnya dari hasil observasi yang dilakukan terhadap guru yang dilakukan tiga kali pertemuan pada awal pembelajaran sampai selesai yang telah dilakukan dengan sentra bahan alam, peneliti mendapati bahwa pembelajran sentra bahan alam untuk meningkatkan kreativitas anak melalui bahan alam pelepah pisang sudah berkembang dengan sangat baik. Hal ini terlihat pada anak umur 4-5 tahun sudah mampu mengkreasikan sendiri berbagai macam bentuk-bentuk melalui media pelepah pisang.

Implementasi model pembelajaran sentra bahan alam dalam meningatkan kreativitas melalui aktifitas bemain menggunakan media pelepah pisang disimpulkan oleh peneliti dilihat dari proses pembelajaran penerapan model pembelajaran sentra bahan alam mampu membangkitkan kreativitas yang dimiliki anak. Hal ini dilihat melalui kegiatan bermain ini anak mengenal berbagai bentuk yang dikreasikan sendiri dan mengenal carcara mencampur warna yang menarik dan meciptakan warna baru untuk digunakan.

Tabel 1 Hasil penilaiaan guru dalam meningkatkan kreativitas anak melalui sentra bahan alam pelepah pisang

\begin{tabular}{|l|l|l|l|l|r|}
\hline No & Indikator & BB & MB & $\begin{array}{l}\text { BS } \\
\text { H }\end{array}$ & BSB \\
\hline 1 & $\begin{array}{l}\text { Anak mampu } \\
\text { bermain dengan } \\
\text { teman }\end{array}$ & & & $\checkmark$ & \\
\hline 2 & $\begin{array}{l}\text { Anak mampu } \\
\text { berfikir kreatif }\end{array}$ & & & & $\checkmark$ \\
\hline 3 & $\begin{array}{l}\text { Anak mampu } \\
\text { memunjulkan ide- } \\
\text { ide bari }\end{array}$ & $\begin{array}{l}\text { Anak mampu } \\
\text { mengahsilkan karya } \\
\text { yang berbeda }\end{array}$ & & & $\checkmark$ \\
\hline
\end{tabular}

Pijakan lingkungan, dilakukan ketika bel berbunyi menandakan bahwa memasuki kelas segera tiba, ketika anak mendengarkan bel langsung bersiap untuk berbaris di depan kelas lalu guru mengajak anak membaca beberapa doa, hadis gerakan dan bernyanyi, biasanya guru menggunakan cara yang unik untuk anak berjalan memasuki kelas. Sebelumnya guru sudah menata ruang untuk bermain anak dengan baik dan aman 
Jurnal PG-PAUD Trunojoyo: Jurnal Pendidikan dan Pembelajaran Anak Usia Dini, Volume 8, Nomor 2, Oktober 2021, hal 1-9, ISSN: 2528-3553 (online), ISSN: 2407-4454 (print)

digunakan oleh anak, selanjutnya diskusi dengan tema yang diterapkan pada hari tersebut dan mengikuti kegiatan sesuai dengan SOP yang biasa diterapkan seperti: membaca doa harian, asma'ulhusna. Setelah pembukaan masuk kedalam kegiatan inti, disini anak masuk kedalam rombel sentra yang telah disediakan.

Pijakan sebelum bermain, merupakankan aktifitas yang dilakukan sebelum brosesbermain berlangsung, seperti mendiskusikan tema yang digunakan pada hari tersebut, aturan-aturan selama bermain bermain, mejelaskan tahapan-tahapan bermain dan macam-macam aktifitas bermain yang telah disiapkan oleh guru dan mengenalkan media yang akan digunakan.

Pijakan saat bermain, adalah kegiatan anak dalam sentra bahan alam pada pijakan saat bermain ini adalah anak melakukan aktifitas bermain sesuai dengan densitas yang telah diberikan oleh guru. Adapun pijakan setelah bermain dilakukan setelah kegiatan bermain selesai biasanya kegiatan pijakan setelah bermain ini adalah kegiatan penutup seperti recalling, penguatan tetang permainan hari ini, siapa yang sudah mengikuti aturan bermain, dan membahas ulang kegiatan bermain hari ini, menyampaikan hasil karya anak dan melakukan kegitan penutup sesuai SOP seperti baca doa keluar rumah, doa naik kenderaan darat, doa selamat dari bahaya dan selawat. Hal ini sesuai dengan keputusan dalam (Depdiknas, 2007).

Langkah-langkah model pembelajaran sentra ini seorang guru harus menata ruang bermain anak, penataan ini diciptakan selaras dengan kerangka pembelajaran yang telah disetujui oleh kepala sekolah. Kemudian diawal ada kegiatan pembukaan dilaksakan kerang lebih selama 30 menit, kegiatan yang berada dalam kegiatan pembukaan antara lain: pengalaman gerak kasar, diskusi tema, SOP (kegiatan-kegiatan yang selalu dilakukan didalam lembaga tersebut). Selanjutnya berlanjut kedalam materi pagi selama kurang lebih 30-45 menit, materi ini pelakasaan pembelajaran yang dilakukan diluar kegiatan inti sentra, digunakan untuk mensiasati adanya buku atau LKS yang telah digunakan di sekolah tersebut. Setelah kegiatan pagi dialkukan dilanjutkan dengan istirahat selama 30 menit. Selanjutnya anak-anak dikondisikan masuk kedalam sentra masing-masing sesuai dengan sentra yang telah disiapkan pada hari tersebut disinilah kegiatan inti atau kegiatan sentra itu berjalan biasanya dilakukan kurang lebih 1 jam setegah. Setelah kegiatan berakhir anak dikumpulkan kedalam satu kelompok untuk melakukan kegiatan penutup, kegaitan penutup ini biasanya berisi tentang diskusi, kegiatan esok hari dan SOP sebelum pulang biasanya kegiatan ini biasanya memakan waktu sekitaran 10 menit.

\section{Pembahasan}

Hasil implementasi model pembelajar sentra bahan alam menggunkan pelepah pisang terbukti dapat meningkatkan kreativitas anak melalui, hal yang saja juga terdapat dalam jurnal (Nurani, 2017) memberikan informasi bahwa salah satu cara meningkatkan kreativitas anak adalah melalui kegiatan bermain peran. Sependapat dengan itu terdapa dalam jurnal (Ubaidillah, 2018) pada sentra BAC (bahan alam cair) mampu meningkatkan kreativitas pada anak.

Dari pendapat diatas dapat disimpulkan bahwa menerapan model pemebelajaran mampu meningkatkan kreativitas pada anak.

\section{SIMPULAN}

Berdasarkan reaksi dari penelitian yang telah berjalan di TKN Pembina Sawang dengan judul implementasi model pembelajaran sentra bahan alam untuk meningkatkan kreativitas pada anak umur 4-5 tahun, dapat ditarik kesimpulan bahwasanya penerapan model pembelajaran sentra bahan alam 
Jurnal PG-PAUD Trunojoyo: Jurnal Pendidikan dan Pembelajaran Anak Usia Dini, Volume 8, Nomor 2, Oktober 2021, hal 1-9, ISSN: 2528-3553 (online), ISSN: 2407-4454 (print)

terdapat peningkatkan kreativitas yang dimiliki anak. Hal ini dibuktikan dari hasil kerja yang dilakukan anak sudah mampu mengkreasikan berbagai betuk dan berbagai macam gambar menggunakn pelapah pisang yang disedian disentra bahan alam

Implementasi model pembelajaran sentra bahan alam dalam meningatkan kreativitas melalui aktivitas bemain menggunakan media pelepah pisang disimpulkan oleh peneliti dilihat dari proses pembelajaran implementasi model pembelajaran sentra bahan alam mampu menumbuhkan kreativitas yang dimiliki anak. Hal ini dilihat melalui kegiatan bermain ini anak mengenal berbagai bentuk yang dikreasikan sendiri dan mengenal caracara mencampur warna yang menarik dan meciptakan warna baru untuk digunakan kembali.

\section{SARAN}

Berdasarkan pengamatan peneliti: didalam pembuatan RPPH diharapkan untuk mencantumkan KD (standar kompetensi). Agar pencapaian pada suatu proses pembelajaran terlaksanakan secara terstruktur. Diharapkan kepada guru dalam penerapan model pembelajaran sentra bahan alam ini untuk memanfaatkan bahan yang berasal dari alam bisa apa saja asalkan tidak membahayakan anak.

Pada penelitian ini masih terdapat kekurang baik dari segi teori maupun tulisan, dalam hal ini peneliti mengharapakn kritikan dan saran agar dapat memperbaiki di penelitian selanjutnya.

\section{DAFTAR PUSTAKA}

Dahlia, S. (2014). Implementasi dan inovasi kurikulum PAUD 2013. Bandung: PT Remaja Rosdakarya.

Depdiknas. (2007). Pedoman penerapan pendekatan "beyond centers and circle time (BCCT)" (Pendekatan sentra dan lingkaran) dalam pendidikan anak usia dini. Direktorat pendidikan dan tenaga kependidikan non formal.

Freeman. (2004). Cerdas dan Cemerlang. Jakarta: PT Gramedia Pustaka Utama.

Ghofur, A. (2017). Pengelolaan Pembelajaran Sentra pada Anak Usia Dini di Kelompok Bermain Universal Ananda Desa Purwokerto Kecamatan Patebon Kabupaten Kendal. Ekp, 13(3), 1576-1580.

Hafiza, H. (2019). Penerapan model pembelajaran sentra (beyond centers and circle time) dalam mengoptimalkan aspek kognitif pada kelompok $B R A$ Syihabuddin Malang. http://etheses.uinmalang.ac.id/id/eprint/16712

Lestarini, Y., Marhaeni, A. A. I. N., \& Suastra, W. (2013). Penerapan Model Pembelajaran Beyond Centers and Circle Time (BCCT) untuk Meningkatkan Minat dan Aktivitas Belajar Anak Kelompok B TK Bumi Gora BPKBM NTB. e-Journal Program Pascasarjana Universitas Pendidikan Ganesha, 3.

Mukhtar Latif, D. (2013). orientasi baru pendidikan anak usia dini: teori dan aplikasi. Jakarta: PT fajar interpratama mandiri.

Munandar, U. (2009). Mengembangkan Kreativitas Anak Berbakat. Yogyakarta: Rineka Cipta.

Nasional, D. P. (2004). Undang-undang Sistem Pendidikan Nasional. Depdiknas.

Nurani, Y. (2017). Pengembangan Model Kegiatan Sentra Bermain Dalam Mengembangkan Kreativitas Anak Usia Dini. JPUD - Jurnal Pendidikan Usia Dini, 11(2), 386-400. https://doi.org/10.21009/jpud.112.15

Nurhayati, E. (2011). Psikologi Pendidikan Inovatif. Yogyakarta: Pustaka Pelajar.

Rachmawati. (2011). Strategi Pengembangan Kreativitas pada Anak Usia Taman Kanak-Kanak,.Yogyakarta: 
Jurnal PG-PAUD Trunojoyo: Jurnal Pendidikan dan Pembelajaran Anak Usia Dini, Volume 8, Nomor 2, Oktober 2021, hal 1-9, ISSN: 2528-3553 (online), ISSN: 2407-4454 (print)

Kencana.

Rasyid, H. (2020). Hakikat pendidikan anak usia dini. Yogyakarta: insan madani.

Retno Soendari, dan Wismiarti. (2010). Sentra persiapan. Yogyakarta: Penerbit pustaka Al- Falah.

Sudjarwo, dan Basrowi. (2009). Manajemen penelitian sosial. Bandung: cv. mandar maju.

Suhartini, P. (2016). Pengembangan kreativitas anak usia dini melalui metode bermain dengan permainan balok di Taman Kanak-Kanak Sabrina Sukarame Bandar Lampung.

Susanti, R. D. (2012). Esai-Esai Pendidikan Islam: Pengembangan Interaksi dengan Lingkungan dan Potensi Anak. Yogyakarta: Idea Press.

Suyadi. (2014). teori pembelajaran anak usia dini. PT Remaja Rosdakarya.

Ubaidillah, K. (2018). Pembelajaran Sentra BAC (Bahan Alam Cair) untuk Mengembangkan Kreativitas Anak; Studi Kasus RA Ar-Rasyid. Al-Athfal: Jurnal Pendidikan Anak, 4(2), 161-176. https://doi.org/10.14421/alathfal.2018.42-04

Yusuf, Farida D. (2018). Pedoman pengelolaan kelas pendidikan anak usia dini. Direktorat pembinaan pendidikan anak usia dini. 